\title{
FITTING AUSGeoid98 TO THE AUSTRALIAN HEIGHT DATUM USING GPS-LEVELLING AND LEAST SQUARES COLLOCATION: APPLICATION OF A CROSS-VALIDATION TECHNIQUE
}

\author{
W. E. Featherstone and D. M. Sproule \\ Western Australian Centre for Geodesy, Curtin University of Technology, \\ GPO Box U1987, Perth, WA 6845, Australia \\ Tel: +61 89266 2734, Fax: +61 89266 2703, Email: W.Featherstone@curtin.edu.au
}

\begin{abstract}
In an absolute sense and over long (>100 km) baselines, the AUSGeoid98 gravimetric-only geoid model does not always allow the accurate transformation of Global Positioning System (GPS)-derived ellipsoidal heights to Australian Height Datum (AHD) heights in all regions of Australia. This is due predominantly to the well-known biases and distortions in the AHD, but long-wavelength errors in the gravimetric geoid model or GPS errors cannot be ruled out. Until the AHD is rigorously redefined, an interim solution is sought where co-located GPS and AHD heights are used to distort AUSGeoid98 such that it provides a better model of the separation between the base of the AHD and the GRS80 reference ellipsoid. This data combination was implemented using least squares collocation (LSC) gridding. Importantly, GPS-AHD data not used in the LSC combination were used to assess the improvement using a cross-validation technique. Using this cross-validation, RMS noise of $14 \mathrm{~mm}$ and correlation length of $2500 \mathrm{~km}$ for the LSC covariance function were optimised empirically. The standard deviation of the differences between the final combined model and the unused GPS-AHD data is $\pm 156 \mathrm{~mm}$, compared to $\pm 282 \mathrm{~mm}$ for AUSGeoid98 alone. It is anticipated that the same technique will be used to produce a new Australian "geoid" model.
\end{abstract}

\section{INTRODUCTION AND BACKGROUND}

As taught in most textbooks, knowledge of the position of the geoid $(N)$ with respect to the WGS84 ellipsoid is required to transform GPS-derived ellipsoidal heights $(h)$ to physically meaningful orthometric heights $(H)$, acknowledging the [small] curvature of the plumblines (i.e., $H \approx h-N$ ). While this is true in theory, distortions in the realisation of the local vertical datum for heights approximating $H$, as well as errors in $N$ and $h$, dictate that it is not always true in practice (e.g., [4, 10]). The many other subtle reasons for this will be covered in a separate paper to be submitted to the Journal of Geodesy. The "bottom line" is that using a gravimetric-only geoid model will not always deliver GPS-derived orthometric heights that are fully compatible with the local vertical datum. As such, GPS and a gravimetric-only geoid model cannot always replace geodetic spirit levelling. The same arguments apply to normal heights derived from GPS and a quasi-geoid model.

In Australia, the AUSGeoid98 gravimetric geoid model of $N_{A G 98}$ [12], while yielding improvements over its predecessors [9], does not always deliver an improved transformation of GPS-derived $h$ to Australian Height Datum (AHD; [27]) height $H_{A H D}$. This occurs in a relative sense when compared to Australian class $\mathrm{C}$ spirit levelling [16], especially over long $(>100 \mathrm{~km})$ GPS baselines, where the benefit of cancellation of common errors no longer always applies (cf. [18]). In an absolute 
sense, e.g., when AUSGeoid98 is used in conjunction with the AUSPOS single-point GPS processing service [10], it can also perform poorly with absolute height differences between GPS-AUSGeoid98 and the AHD reaching $\sim 1 \mathrm{~m}$ (shown later). The principal reason is that there is an inconsistency between the [1971] realisation of the currently used AHD and AUSGeoid98 (cf. [4, 7, 19]).

It is well known that the AHD contains nation-wide distortions of $\sim 1.5 \mathrm{~m}$ or more [27], with a dominant north-south trend, which is most probably due to un-modelled sea surface topography effects on the 32 tide gauges held fixed in the realisation of the AHD [4, 7]. The AHD uses a so-called normal orthometric height system, where normal gravity was used to apply orthometric corrections based on a truncated and approximate formula [27]. Finally, the AHD is contaminated with gross errors, such as the $1-\mathrm{m}$ discrepancy along the Queensland coast between spirit levelling and oceanographic data [14], which is known to be a spirit levelling blunder [25].

Given that the Intergovernmental Committee on Surveying and Mapping (ICSM) has now chosen to adopt the AHD for the foreseeable future, it is necessary from the users' point of view to provide an interim solution for the more direct transformation of GPS ellipsoidal heights to the AHD. At present, many high-precision GPS users in Australia have to apply post-survey adjustments to the GPS-AUSGeoid98-derived heights $\left(H_{A G 98}\right)$ to make them compatible with the AHD [11]. Clearly, this adds effort and cost, and is impractical for real-time GPS applications.

Instead of redefining and recomputing a modern AHD (which the first-named author is a strong advocate of), this practical problem can be solved on an interim basis by combining a gravimetric-only geoid model with high-quality nation-wide GPS and AHD data. Importantly, this combined approach alters the definition of the problem to become the determination of the separation between the AHD and the GRS80 reference ellipsoid, rather than the determination of the classical equipotential geoid (see the more detailed discussion in [4]).

This paper describes the fitting [warping] of AUSGeoid98 to a recent nation-wide set of GPS-AHD data provided by Geoscience Australia in order to provide a better transformation surface for GPS heighting in Australia. Many parametric or surfacefitting options exist (e.g., [13, 2, 20]), but least squares collocation (LSC; [24]) was adopted for this study since it gave the best fit to the GPS and AHD data in the Perth region [5], as well as being used successfully in many other countries (e.g., [23, 1, 2, $22,28,21,17])$.

Importantly, it should be noted that almost all other authors call this the generation of a 'corrector surface' to the geoid. This is a misnomer because the error does not lie entirely in the geoid model; it also lies in the GPS and levelling data (especially so for the distorted AHD). It is conceivable that AUSGeoid98 provides a better model of the classical equipotential geoid over Australia, but does not accurately model the [distorted] AHD. As such, the 'corrector surface' terminology will be avoided here, and should probably be avoided elsewhere.

Similarly, many authors incorrectly call the product of fitting the gravimetric-only geoid model to GPS-levelling data, a geoid (e.g., [28]). It is not the classical geoid, but rather a warped variant that is forced to fit discrete GPS-levelling data often on a distorted local vertical datum. As such, the term geoid should probably be avoided. However, most lay users know that they have to apply a geoid to the GPS data to make water flow 'down hill'. As such, the term geoid could arguably be retained for the fitted product, but with a caveat emptor for the knowledgeable user. 


\section{FITTING AUSGeoid98 TO GPS-AHD USING LSC: CONCEPTS AND PHILOSOPHY}

This task is now defined specifically in terms of providing a model of the separation between the GRS80 ellipsoid and the base of the AHD, rather than determining the classical geoid as an equipotential surface of the Earth's gravity field [4]. The LSC prediction/gridding technique was used in this study, where discrete AHD-GRS80ellipsoid separations derived from GPS observations at AHD benchmarks (i.e., $N_{A H D}=$ $h-H_{A H D}$ ) are used to warp/distort AUSGeoid98 (i.e., $N_{A G 98}$ ) so that it provides a better model of the AHD-GRS80-ellipsoid separation $N_{A H D}$ over Australia.

LSC is essentially a form of Kriging [3], in that when it is used to interpolate data, it makes use of the geographical distribution of and errors in the discrete data used. Another advantage of LSC is that it has already been proven to be effective in previous similar studies (see the citations given in the Introduction). Our LSC data combination uses the GEOGRID routines from the GRAVSOFT suite of computer programs for gravity field modelling and prediction [29, 30]. The tried and tested version of GEOGRID used by [5] was adopted here.

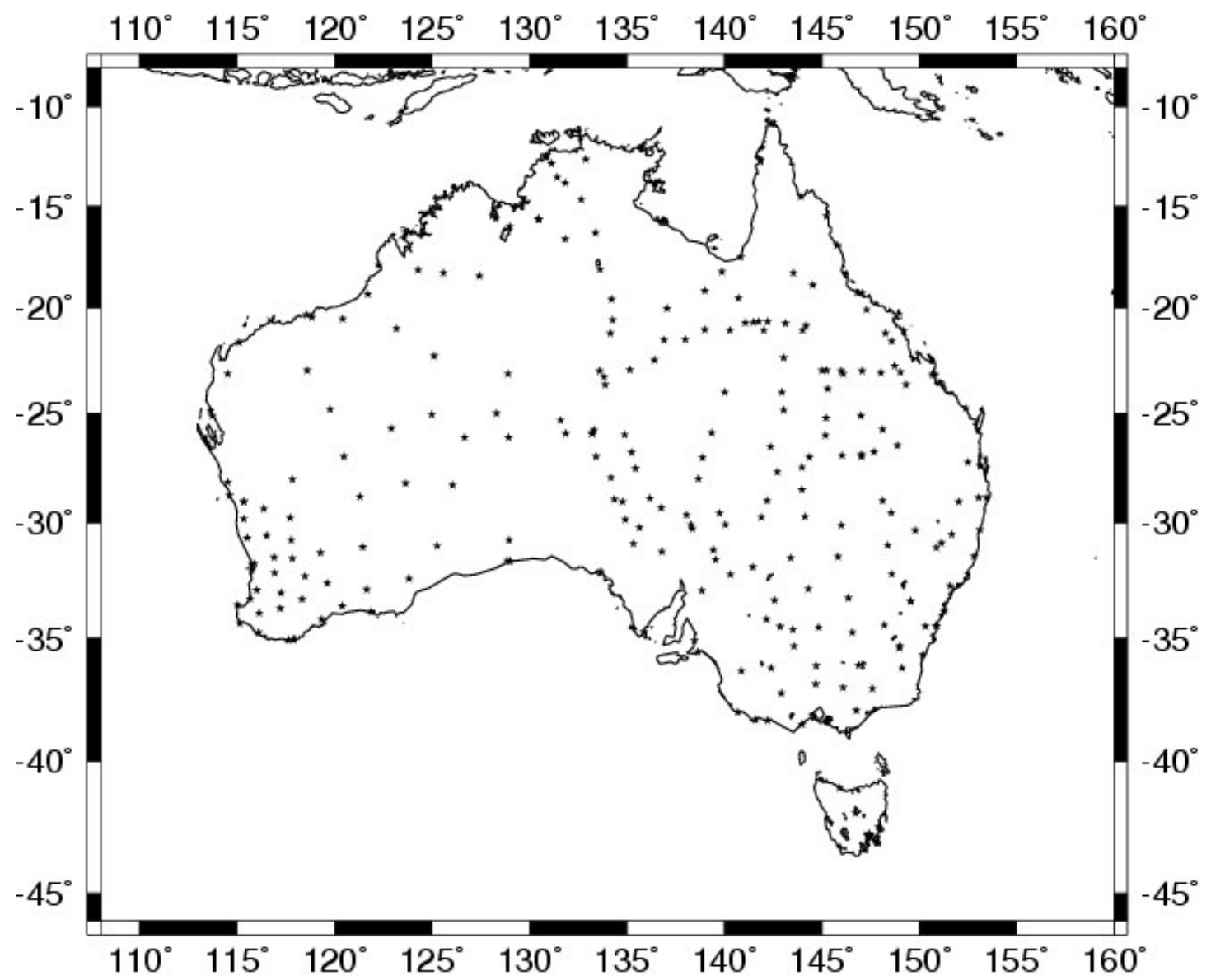

Figure 1. Spatial coverage of the 254 co-located GPS and AHD heights (Mercator projection)

This study used the published 2-arc-minute by 2-arc-minute grid of AUSGeoid98 geoid undulations ([12]; http://www.ga.gov.au/nmd/geodesy/ausgeoid/), which includes the local fit to GPS-AHD data in the Perth region [5], and a set of 254 colocated GPS and AHD heights provided by Geoscience Australia (Figure 1). It is acknowledged that the 1013 GPS-AHD points used by [12] and [9] are now known to contain some large uncertainties, so have been omitted from this study. These 1013 
points were also used to estimate a $\sim 1 \mathrm{~m}$ zero-degree [bias] term in AUSGeoid98 [12], but this also absorbs any constant vertical offset in the AHD (cf. [26]). The 254 GPS heights are tied to the International Terrestrial Reference Frame (ITRF), either via surveys relative to the Geocentric Datum of Australia (GDA) or via single-point carrier-phase GPS processed with the AUSPOS service (Johnston, pers. comm.)

The residuals $\varepsilon$ between the discrete AHD-GRS80-ellipsoid separations $\left(N_{A H D}\right)$, computed at the co-located GPS-AHD stations in Figure 1 (i.e., $N_{A H D}=h-H_{A H D}$ ), and AUSGeoid98-GRS80-ellipsoid separations $\left(N_{A G 98}\right)$, bi-cubically interpolated from the AUSGeoid98 grid, were computed at the GPS-AHD points (i.e., $\varepsilon=N_{A H D}-N_{A G 98}$ ). The residuals $\varepsilon$ were LSC-predicted onto the same 2-arc-minute grid as used by AUSGeoid98, and then added to AUSGeoid98 to produce the combined nation-wide model of $N_{A H D}$. Several combined solutions were computed in order to empirically optimise the correlation length of the covariance function and RMS noise of the GPSAHD data in the LSC prediction process (described later).

Most often, the same GPS-levelling data used to construct the combined model are also used to verify that model (e.g., $[\mathbf{2 3}, \mathbf{1}, \mathbf{2}, \mathbf{2 8}, \mathbf{1 7}])$. This strategy is biased because it is insensitive to errors in the GPS-levelling data. Specifically, any error in the GPSlevelling data will cause the same error in the combined model. However, this error will not be apparent when compared to the same GPS-levelling data (i.e., the same data are used both to create and test the combined model).

Therefore, a cross-validation technique is used in this study, where one GPSlevelling point is omitted from each LSC prediction, then that point is used to assess the combined model. This is repeated for all points in the dataset (254 LSC runs in this case). Importantly, this gives a more objective assessment of the combined solution, rather than using the same data twice, once to create the combined model, then again to verify that model.

Visual comparisons were also used as a further check for any discontinuities in the combined model. The combined model that yielded the best overall fit to the unused GPS-AHD data was deemed to be the optimal model of the separation between the base of the AHD and GRS80 $\left(N_{A H D}\right)$.

\section{FITTING AUSGeoid98 TO GPS-AHD USING LSC: METHODS AND RESULTS}

\section{Outlier detection}

Following [9] and using the software and techniques in [6], the absolute and relative fits of AUSGeoid98 to the 254 GPS-AHD data were first determined (Tables 1 and 2). The tests were applied in an absolute sense, where the differences at the 254 control points were used (Figure 1), and in a relative sense, where the differences over all 32,131 possible $(m=n(n-1) / 2$, where $n$ is the number of stations) baselines were used.

Table 1. Descriptive statistics of the absolute differences (residuals $\varepsilon$ ) between the 254 GPS-AHD stations and AUSGeoid98 (units in metres)

\begin{tabular}{c|cccccc}
\hline & Max & Min & Mean & STD & RMS & Outliers \\
\hline Inc outliers & 0.865 & -0.721 & 0.076 & \pm 0.286 & \pm 0.295 & $1(0.4 \%)$ \\
Exc outliers & 0.780 & -0.721 & 0.073 & \pm 0.282 & \pm 0.291 & 0 \\
\hline
\end{tabular}

First, the results in the second row of Tables 1 and 2 are slightly better than those presented in [9], which reflects the better quality of the new GPS-AHD data. However, Table 1 shows that if AUSGeoid98 is used in an absolute sense, e.g., in conjunction 
with AUSPOS [10], residuals $\varepsilon$ of up to $0.780 \mathrm{~m}$ remain, which is clearly unacceptable if AUSPOS and AUSGeoid98 are to be used to replace sprit levelling from existing AHD benchmarks.

Table 2. Descriptive statistics of the relative differences $(\Delta \varepsilon)$ between the control data and AUSGeoid98 over $m=31,878$ baselines (units in metres), and the mean difference in parts per million $(\mathrm{mm} / \mathrm{km})$ of baseline length. The row excluding outliers only excludes the one outlier detected in Table 1.

\begin{tabular}{c|ccccccc}
\hline & Max & Min & Mean & STD & RMS & Outliers & Mean ppm \\
\hline Inc outliers & 1.409 & -1.587 & 0.012 & \pm 0.404 & \pm 0.405 & $46(0.14 \%)$ & 2.246 \\
Exc outliers & 1.409 & -1.501 & 0.017 & \pm 0.399 & \pm 0.399 & $37(0.12 \%)$ & 2.260 \\
\hline
\end{tabular}

The outliers in Tables 1 and 2 were determined according to a Z-score of three (i.e., residuals $\varepsilon$ greater than three standard deviations of the mean) under the assumption of a normal distribution of the absolute and relative differences, which is not exact because of systematic errors, notably in the AHD and AUSGeoid98. One GPS-AHD point was identified as an outlier using the absolute testing (Table 1). Without any additional information about the data at this point, it was excluded from further analysis.

\section{Empirical determination of LSC gridding parameters}

LSC prediction was used to grid the absolute residuals between the 253 GPS-AHD and the AUSGeoid98 heights (i.e, $\varepsilon=N_{A H D}-N_{A G 98}$ ) on to the same 2-arc-minute grid as used for AUSGeoid98, and then this predicted residual was added to AUSGeoid98 to give the combined solution $\left(N_{A H D}^{\prime}=\varepsilon+N_{A G 98}\right)$. Importantly, this was done in a cross-validation mode, where one point was omitted from each LSC run, then the new residual $\varepsilon^{\prime}$ between the GPS-AHD height $N_{A H D}$ and the combined solution $N_{A H D}^{\prime}$ calculated at this point (i.e., $\varepsilon^{\prime}=N_{A H D}-N_{A H D}^{\prime}$ ), where the prime has been used throughout to denote the LSC-combined surface. This process was then repeated for all 253 GPS-AHD points and descriptive statistics computed for the unused residuals $\varepsilon^{\prime}$.

The RMS noise of the co-located GPS-AHD data and the correlation length of the covariance function for the LSC prediction were chosen empirically, broadly according to the methods outlined in [5]. The former was necessary because no reliable error information was provided with the GPS-AHD data. Given that we aim to produce a model of the separation between the base of the AHD and GRS80 ellipsoid $\left(N_{A H D}\right.$ ), no RMS noise value need be estimated for the AHD heights $H_{A H D}$. This ensures that the combined surface faithfully fits the AHD benchmarks used, within the likely error of the GPS-derived ellipsoidal heights $h$. The bounds of the RMS noise for $h$ were 10 $\mathrm{mm}$ and $20 \mathrm{~mm}$, and the bounds of the correlation length were $100 \mathrm{~km}$ and $7000 \mathrm{~km}$. This resulted in a total of approximately 30x253 LSC runs, with each set of 253 runs taking $\sim 8$ hours on a Sun Fire R280 workstation (two parallel 1-GHz CPUs and $8 \mathrm{Mb}$ RAM).

Figures 2 and 3 show the RMS of the differences between the unused GPS-AHD data points and the LSC-combined models for variations in the correlation length of the covariance function and the RMS noise of the GPS heights, respectively. The optimal correlation length was determined first because the RMS noise on the GPS heights is relatively easier to estimate, and no RMS noise was assigned to the AHD. From 
Figure 2, there is a clear minimum in the standard deviation for a correlation length of $2,500 \mathrm{~km}$, which was therefore chosen for the final combined solution. The RMS noise was set at $0.014 \mathrm{~mm}$ (Figure 3).

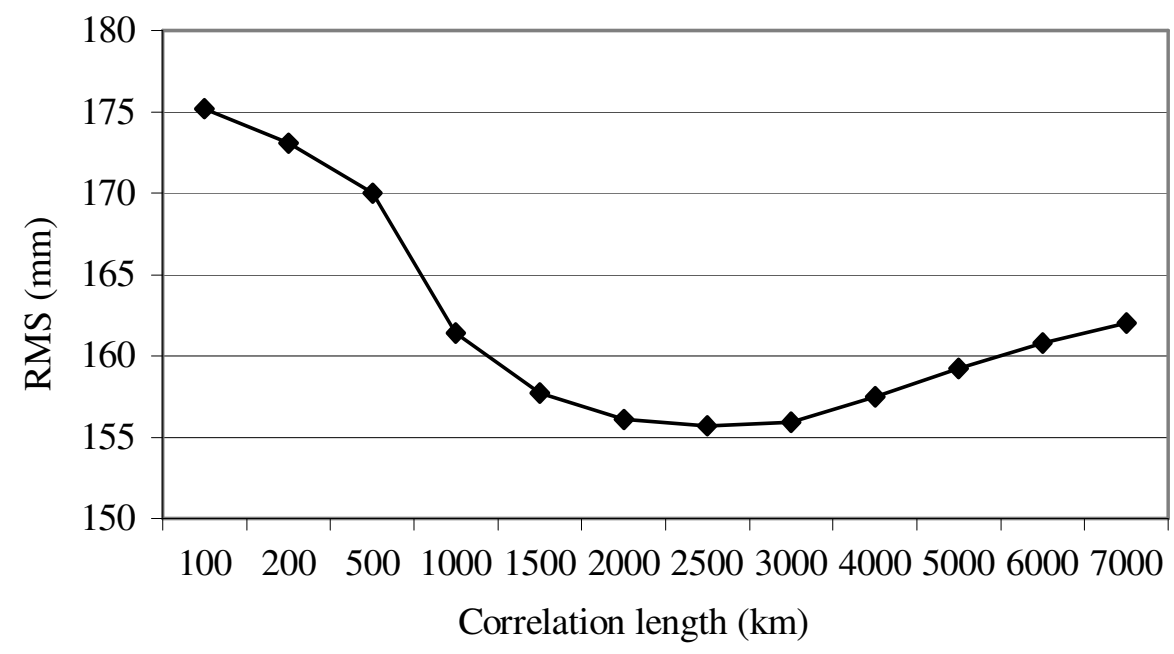

Figure 2. RMS of the differences (in $\mathrm{mm}$ ) between various LSC-combined solutions and the unused GPS-AHD heights as a function of correlation length of the covariance function; RMS noise of the GPS heights was $14 \mathrm{~mm}$.

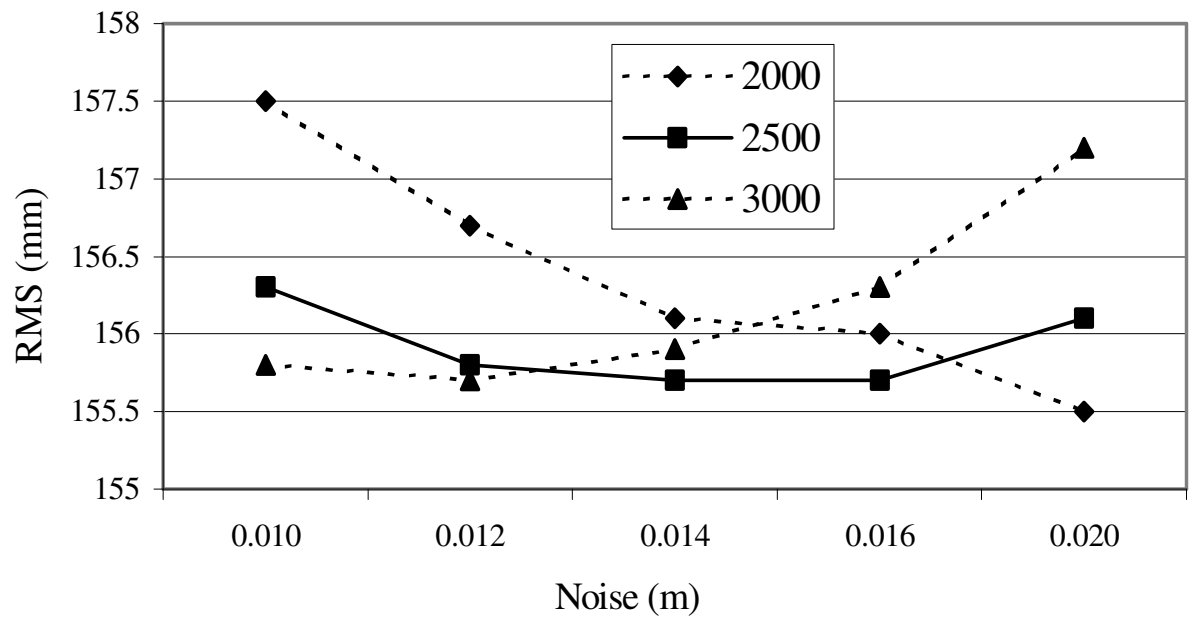

Figure 3. RMS of the differences (in $\mathrm{mm}$ ) between various LSC-combined solutions and the unused GPS-AHD heights as a function of RMS noise of the GPS heights for correlation lengths of 2000, 2500, and $3000 \mathrm{~km}$.

Note that the RMS values in Figures 2 and 3 are larger than reported for other LSCcombined models (e.g., [23, 1, 2, 28, 17]). This is because we have used the crossvalidation approach. If we had used the same GPS-AHD data to both determine the correlation length and RMS noise, and then to test the combined model, the RMS differences would have been much smaller. However, as stated earlier, this gives an over-optimistic indication of precision and is insensitive to GPS-AHD errors.

\section{Warping AUSGeoid98 to the AHD}

Figure 4 shows the final LSC-predicted (RMS noise $14 \mathrm{~mm}$, correlation length 2,500 km) surface of the residuals $\varepsilon$ that was added to AUSGeoid98 to produce the combined model of the separation between the GRS80 ellipsoid and the base of the AHD. Note the predominant north-south trend in Figure 4, which is attributed to distortion in the AHD caused by fixing the tide gauges to local mean sea level, thus neglecting the general north-south trend in the sea surface topography around Australia 
(cf. $[7,8])$.

Given this dominant north-south trend (Figure 4), linear regression was used to determine latitudinal $(\varphi)$ and longitudinal $(\lambda)$ slopes of the residuals $\varepsilon$ (cf. [8]) as

$$
\begin{aligned}
& \varepsilon=0.0303 \varphi+0.9017[\mathrm{~m}] \quad\left(R^{2}=0.558\right) \\
& \varepsilon=0.0007 \lambda-0.0216[\mathrm{~m}] \quad\left(R^{2}=0.001\right)
\end{aligned}
$$

which resolve to give an azimuth of tilt of $\sim 1.3^{\circ}$. The combined model absorbs this north-south tilt, but also accounts for higher order distortions (Figure 4). As such, the LSC combination is superior to using only a planar fit.

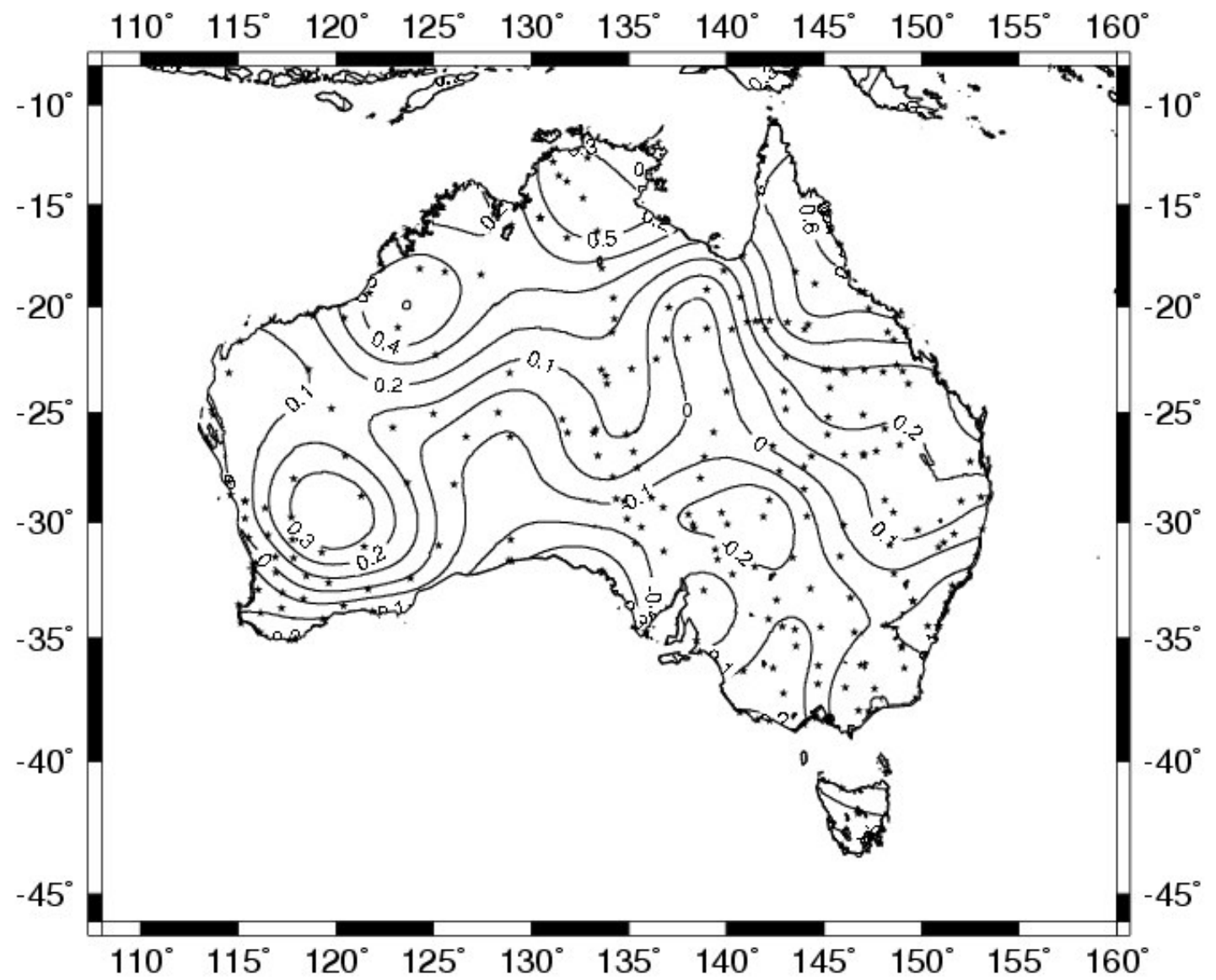

Figure 4. The LSC-predicted surface used to warp AUSGeoid98 such that it provides a better model of the AHD. Note the dominant north-south trend of $\sim 0.3 \mathrm{~mm}$ per $\mathrm{km}$, which is due to the effect of unmodelled sea surface topography on the realisation of the AHD. (Contours in metres; Mercator projection)

Table 3 shows the absolute differences between the 253 GPS-AHD data points and final LSC-combined solution (i.e., correlation length of 2,500 km and RMS noise of 14 $\mathrm{mm})$. This includes the case when all the GPS-AHD data are used to evaluate the combined solution, which gives a better indication of how the combined surface will perform in practice. For comparison, the descriptive statistics for the unused GPSAHD data are also presented in Table 3. Table 4 shows the descriptive statistics for the relative case, using all GPS-AHD data.

Table 3. Descriptive statistics of the absolute differences (post-fit residuals $\varepsilon^{\prime}$ ) between 253 GPS-AHD stations and the final LSC-combined solution (units in metres) 


\begin{tabular}{c|cccccc}
\hline & Max & Min & Mean & STD & RMS & Outliers \\
\hline All GPS-AHD data & 0.462 & -0.483 & 0.000 & \pm 0.118 & \pm 0.118 & $4(1.6 \%)$ \\
Unused GPS-AHD data & 0.525 & -0.603 & -0.002 & \pm 0.156 & \pm 0.156 & $5(2.0 \%)$ \\
\hline
\end{tabular}

Table 4. Descriptive statistics of the relative differences $\left(\Delta \varepsilon^{\prime}\right)$ between the control data and the final LSC-combined solution over 31,878 baselines (units in metres), and the mean difference in parts per million $(\mathrm{mm} / \mathrm{km})$ of baseline length

\begin{tabular}{c|ccccccc}
\hline & Max & Min & Mean & STD & RMS & Outliers & Mean ppm \\
\hline $\begin{array}{c}\text { All GPS-AHD } \\
\text { data }\end{array}$ & 0.945 & -0.791 & 0.017 & \pm 0.166 & \pm 0.167 & $322(1 \%)$ & 2.130 \\
\hline
\end{tabular}

Comparing the results in Table 3 with Table 1 shows that the final LSC-combined solution reduces the RMS of the absolute differences from $291 \mathrm{~mm}$ to $156 \mathrm{~mm}$ $(\sim 54 \%)$. In the relative sense, the RMS is reduced by $\sim 42 \%$ from $399 \mathrm{~mm}$ to $167 \mathrm{~mm}$ (cf. Tables 2 and 4). However, some large absolute differences of $\sim 0.5 \mathrm{~m}$ remain in the combined solution, which combine to close to $1 \mathrm{~m}$ in the relative sense.

Figure 5 shows a map of the post-fit residuals for all 253 GPS-AHD data (cf. Table 3 , row 1). Some of the larger differences occur in places where the GPS-AHD data coverage is sparse, such as in central Western Australia. As such, improved GPSAHD data coverage is needed to refine the combined solution in these regions. However, some larger differences also occur where the GPS-AHD data are denser (e.g., at $28^{\circ} \mathrm{S}, 142^{\circ} \mathrm{E}$ - black circle in Figure 5). Given the $2,500 \mathrm{~km}$ correlation length of the covariance function used, this suggests errors in the data used at these points, though we cannot discriminate which. Nevertheless, this alone confirms the usefulness of the cross-validation approach. 


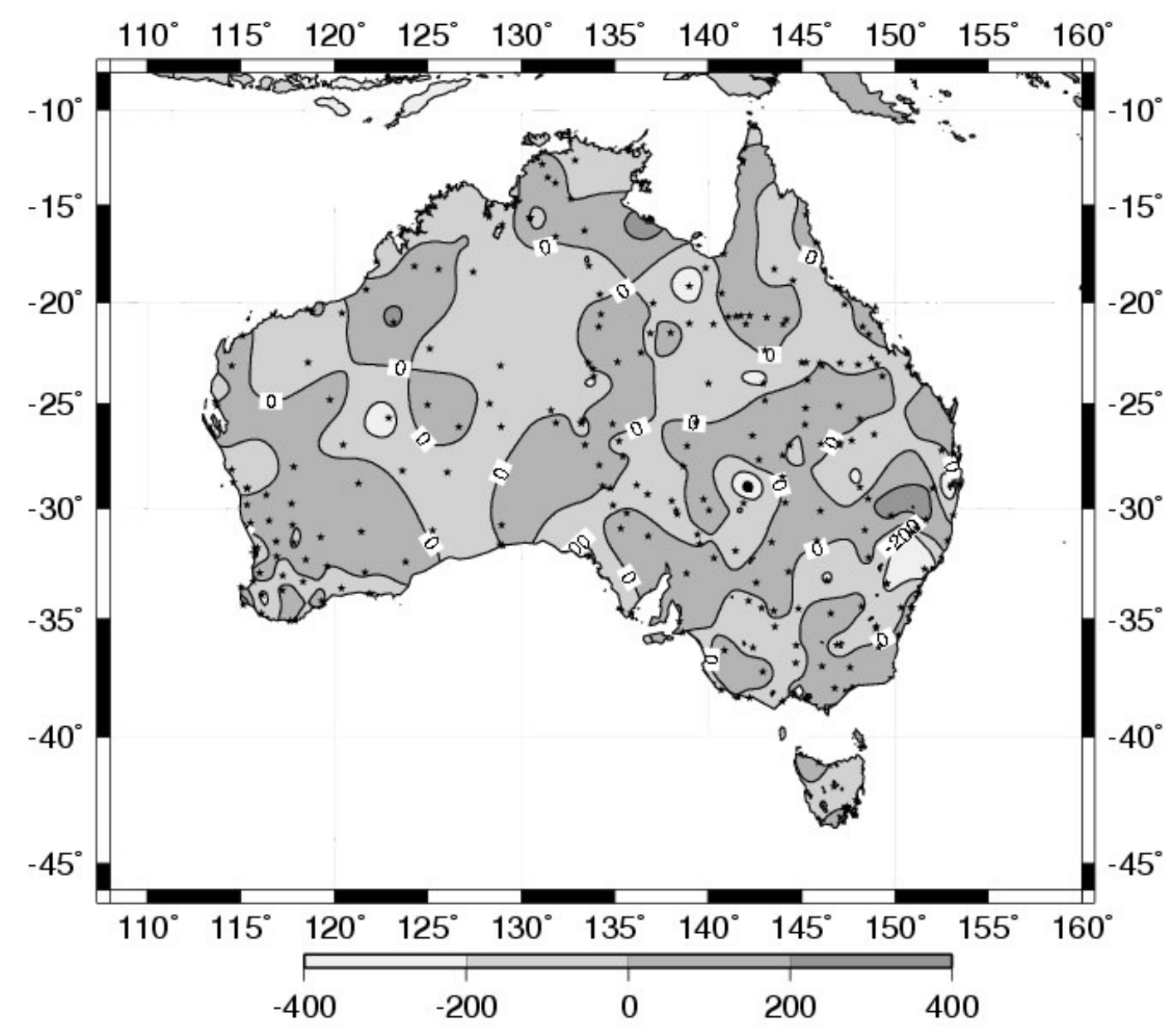

Figure 5. Post-fit differences (in mm) between the final LSC-combined model and 253 GPS-AHD data (Contours in millimetres; Mercator projection)

\section{SUMMARY, CONCLUSION AND RECOMMENDATION}

An LSC-combination of GPS, AHD and AUSGeoid98 data was used to produce a model of the separation between the base of the AHD and the GRS80 ellipsoid. This combined model used a correlation length of 2,500 km and an RMS noise of $\pm 14 \mathrm{~mm}$ for the covariance function, which were determined empirically using a crossvalidation technique. This LSC data combination absorbs a large amount of the discrepancies between AUSGeoid98 and the AHD (assuming the GPS data are correct), and thus supports the more direct transformation of GPS ellipsoidal heights to AHD heights than the gravimetric-only AUSGeoid98.

This technique will be used to create a new "geoid" model for Australia. The inverted commas are used to denote that this is not a model of the classical geoid (see the last paragraph of the Introduction). However, the new combined model will be based on a refined gravimetric geoid, which will include the version 2 GEODATA 9arc-second DEM of Australia and significantly improved global geopotential models derived from the GRACE dedicated satellite gravimetry mission.

The LSC data combination provides a substantial improvement in GPS heighting upon the gravimetric-only AUSGeoid98. For instance, the standard deviation of the (absolute) fit to the GPS-AHD data has improved upon AUSGeoid98 by 54\%. As the GPS-derived AHD height differences do not exhibit the square root of distance error propagation used for spirit levelling [10], the mean discrepancy in terms of $\mathrm{mm} / \mathrm{km}$ (i.e., parts per million (ppm)) of baseline length is used. This is reduced from 2.26 
ppm for the gravimetric-only AUSGeoid98 to $2.13 \mathrm{ppm}$ for the LSC combination, which applies over baselines up to $3,955 \mathrm{~km}$ (mean $\sim 1,700 \mathrm{~km}$ ).

While this combined solution satisfies the interim objective of a more direct determination of AHD heights from GPS than AUSGeoid98, it leaves open the question as to why there are differences between AUSGeoid98 and the AHD. Therefore, it is important to continue research into gravimetric geoid determination and vertical datum definition to explain, account for and possibly correct this difference. Also, the current realisation of the AHD should be critically reviewed and perhaps redefined to make better use of improved datasets and theories that are now available.

\section{ACKNOWLEDGEMENTS}

We would like to thank Gary Johnston at Geoscience Australia for providing the GPS-AHD data. This work is funded by Australian Research Council grant DP0211827 to Featherstone on "Investigations of the integrity of the Australian Height Datum". We would especially like to thank the reviewers (C.C. Tscherning and anonymous) and Editor-in-Chief for their extraordinarily prompt review of this manuscript. We also thank these reviewers for their very constructive critiques, which we feel have clarified a number of points in this revised manuscript.

\section{References}

1. Birardi, G., Santarsiero, D., Tufillaro, D. and Surace, L., 1995. Setting up Local "Mapping Geoids" with the Aid of GPS/LEV Traverses: Application to the Geoids of Sardinia and Calibra. Journal of Geodesy 70(2): 98-109.

2. Denker, H., Torge, W., Wenzel, H.-G., Ihde, J. and Schirmer, U., 2000. Investigation of Different Methods for the Combination of Gravity and GPS/Levelling Data, in: Schwarz K.-P. (ed.) Geodesy Beyond 2000: The Challenges of the First Decade, Springer, Berlin Heidelberg New York, pp 137-142.

3. Dermanis, A., 1984. Kriging and Collocation - A Comparison, manuscripta geodaetica 9(3): 159-167.

4. Featherstone, W.E., 1998. Do we need a Gravimetric Geoid or a Model of the Base of the Australian Height Datum to Transform GPS Heights? The Australian Surveyor 43(4): 273-280.

5. Featherstone, W.E., 2000. Refinement of a Gravimetric Geoid Using GPS and Levelling Data, Journal of Surveying Engineering, 126(2): 27-56.

6. Featherstone, W.E., 2001. Absolute and Relative Testing of Gravimetric Geoid Models Using Global Positioning System and Orthometric Height Data, Computers \& Geosciences, 27(7): 807-814.

7. Featherstone, W.E., 2002. Prospects for the Australian Height Datum and Geoid Model, in: Adam, J. and Schwarz, K.-P (eds) Vistas for Geodesy in the New Millennium, Springer, Berlin Heidelberg New York, pp 96-101.

8. Featherstone, W.E., 2004. Evidence of a North-South Trend Between AUSGeoid98 and the AHD in Southwest Australia, Survey Review 37(291): 334-343.

9. Featherstone, W.E. and Guo, W., 2001. A Spatial Evaluation of the Precision of AUSGeoid98 Versus AUSGeoid93 Using GPS and Levelling Data, Geomatics Research Australasia, 74: 75-102.

10. Featherstone, W.E. and Dent, V., 2002. Transfer of Vertical Control Using Only One GPS Receiver: A Case Study, The Australian Surveyor 47(1): 31-37.

11. Featherstone, W.E., Dentith, M.C. and Kirby, J.F., 1998. Strategies for the Accurate Determination of Orthometric Heights from GPS. Survey Review 34(267): 278-296.

12. Featherstone, W.E., Kirby, J.F., Kearsley, A.H.W., Gilliland, J.R., Johnston, G.M., Steed, J., Forsberg, R. and Sideris, M.G., 2001. The AUSGeoid98 Geoid Model of Australia: Data Treatment, Computations and Comparisons with GPS-Levelling Data, Journal of Geodesy, 75(5-6): 313-330

13. Fotopoulos, G., Featherstone, W.E. and Sideris, M.G., 2003 Fitting a Gravimetric Geoid Model to the Australian Height Datum via GPS Data, in: Tziavos, I.N. (ed) Gravity and 
Geoid 2002, Department of Surveying and Geodesy, Aristotle University of Thessaloniki, Thessaloniki, pp 173-178.

14. Hamon, B.V. and Greig, M.A., 1972. Mean Sea Level in Relation to Geodetic Land Levelling Around Australia, Journal of Geophysical Research - Solid Earth, 77: 71577162.

15. Hipkin RG (2000) Modelling the Geoid and Sea-Surface Topography in Coastal Areas, Physics and Chemistry of the Earth (Series A) 25(1): 9-16.

16. ICSM, 2002. Standards and Practices for Control Surveys (version 1.5), InterGovernmental Committee on Surveying and Mapping, Canberra, [http://www.icsm.gov.au/icsm/publications/sp1/sp1.htm]

17. Iliffe, J.C., Ziebart, M., Cross, P.A., Forsberg, R., Strykowski, G. and Tscherning C.C., 2003. OSGM02: A New Model for Converting GPS-Derived Heights to Local Height Datums in Great Britain and Ireland, Survey Review 37(290): 276-293.

18. Kearsley, A.H.W., 1988. Tests on the Recovery of Precise Geoid Height Differences From Gravimetry, Journal of Geophysical Research 93(B6): 6559-6570.

19. Kearsley, A.H.W., Ahmad, Z. and Chan, A., 1993. National Height Datums, Levelling, GPS Heights and Geoids, Australian Journal of Geodesy Photogrammetry and Surveying 59: 53-88.

20. Kotsakis, C. and Sideris, M.G. 1999. On the Adjustment of Combined GPS/Levelling/Geoid Networks. Journal of Geodesy 73(8): 412-421.

21. Kuroishi, Y., Ando, H. and Fukuda, Y., 2002. A New Hybrid Geoid Model for Japan, GSIGEO2000, Journal of Geodesy 76(8): 428-436.

22. Lyszkowicz, A., 2000. Improvement of the Quasigeoid Model in Poland by GPS and Levelling Data, Artificial Satellites 35(1): 3-8.

23. Milbert, D.G., 1995. Improvement of a High-resolution Geoid Model in the United States by GPS Height on NAVD88 Benchmarks, International Geoid Service Bulletin 4: 13-36.

24. Moritz, H., 1980. Advanced Physical Geodesy, Wichmann, Karlsruhe.

25. National Mapping Council, 1986. Australian Geodetic Datum Technical Manual, Special Publication 10, National Mapping Council of Australia, Canberra, 62 pp.

26. Rapp, R.H., 1994. Separation Between Reference Surfaces of Selected Vertical Datums, Bulletin Géodésique, 69(1): 26-31.

27. Roelse, A., Granger, H.W. and Graham, J.W., 1971. The Adjustment of the Australian Levelling Survey 1970 - 1971, Technical Report 12, Division of National Mapping, Canberra, $81 \mathrm{pp}$

28. Smith, D.A. and Roman, D.R., 2001. GEOID99 and G99SSS: 1-Arc-Minute Geoid Models for the United States, Journal of Geodesy 75(9-10): 469-490.

29. Tscherning, C.C., Forsberg, R. and Knudsen, P., 1992. The GRAVSOFT Package for Geoid Determination, in Holota, P. and Vermeer, M. (eds), Proceedings of the First Continental Workshop on the Geoid in Europe, Prague, pp 327-334

30. Tscherning, C.C., 1992. GEOCOL - A FORTRAN Program for Gravity Field Approximation by Collocation ( $10^{\text {th }}$ edition). Technical Note, Geophysical Department, University of Copenhagen, Copenhagen

31. Zhong, D., 1997. Robust Estimation and Optimal Selection of Polynomial Parameters for the Interpolation of GPS Geoid Heights. Journal of Geodesy 71(9): 552-561. 